\title{
Investigation on the Stability and Dynamic Response of Soil Foundation Under Heavy Haul Railway Tracks
}

\author{
Mrs. Bonthu Santhoshipoornima \\ Department of Civil Engineering \\ Sanketika Institute of Technology \& Management \\ Visakhapatnam-530041, India
}

\author{
Dr. N. C. Anil (Guide) \\ Department of Civil Engineering \\ Sanketika Institute of Technology \& Management \\ Visakhapatnam-530041, India
}

\begin{abstract}
The roadbed is the most deformable and most heterogeneous segment of the railroad track foundation, which states the principle factor deciding the efficiency of the street, and the primary factor behind deterioration of path and its components, leading to the rise in the expense of current maintenance. Notwithstanding the expanding dynamic effect of trains on the railroad framework resulting from heavy haul transportation system, this issue turns out to be especially significant. In this paper, an examination is made of the issue of degradation and giving the strength to the track foundation with an increased axial load on the track, with a strict attention on examination of the excitation mechanisms of cyclic effects and the procedure of their damping by the soil environment. The principle kinds of deformations and defects are portrayed; the mechanisms and explanations behind their occurrence are studied in this paper. Much consideration is paid to the investigation of soil degradation procedures of the roadbed under the dynamic effect of heavy trains. Different components of the roadbed are taken into account, which require support for operation under substantial heavy traffic and huge axial loads. The advanced strategies and structures of strengthening the roadbed are portrayed, the utilization of which permits to build the proficiency of the heavy haul transportation. Taking everything into account, extensive research is carried out to address the issue of ensuring the stability of the roadbed in the association of heavy haul traffic.
\end{abstract}

Keywords-Heavy haul traffic, degradation of track foundation, dynamic effect of heavy trains, stability of track foundation.

\section{INTRODUCTION}

All over the world, the growth in weight norms of freight trains is one of the priority to meet the increasing volumes of cargo transportation and improving the efficiency of railways in market conditions. The heavy haul traffic has developed significantly in different countries on all continents: Australia, Brazil, India, Canada, China, Russia, USA, Sweden, South Africa, becoming one of the main indicators of technological progress of railway transportation at the present stage of railway development.

The operation of longer and heavier trains provides significant benefits in terms of carrying capacity, operating expenses and the cost of a rolling stock. At the same time, the introduction of the increased weight and length of freight trains inevitably increases the costs associated with changing the longitudinal dynamics of the train and the emergence of additional loads on the infrastructure. There are large dynamic shock loads having a very high intensity and short duration, depending on the nature of the oscillations of the wheels or rails, and also on the dynamic response of the base. A large cyclic load from trains with heavy axle loads operating at high speeds often causes excessive deformation and degradation of rail track elements. This problem is most acute with regard to the fundamental element of the construction of the railway the roadbed (foundation), which in many sections of the railways was built according to the technical norms of previous years, not designed for increased axle loads, and which, unlike the top of the railway, operation was not replaced or updated. The loss of stability of the roadbed and, as a consequence of the geometry of the path, inevitably entails a significant increase in the cost of servicing the railway track, estimated in different countries by hundreds of millions of dollars per year.

The railway track formation is a complex of ground objects that function in difficult conditions of the natural and climatic environment and dynamic train loads. Such loads can change the state of the ground environment and affect the level of reliability of the roadbed, especially under conditions of heavy haul traffic, in which the amplitude and frequency of loading cycles are very high.

The degree of displacement of the track under the train load is largely determined by the characteristics of the roadbed soil, which are distinguished by a wide variety, and has a tendency to rapidly change over time. During long-term operation, the railway roadbed is affected by adverse environmental impacts (temperature, water, etc.).

As a result, transformations occur in the soils over time. Namely, the physical and mechanical properties, moisture regime, density, and, as a consequence, the stressstrain state of the roadbed as a whole change. For this reason, the roadbed has a huge impact on the operation of the railway and its maintenance. The railway track, which has been stable for a long time, can begin to deteriorate after applying large axial loads typical for heavy haul rolling stock, resulting in a failure to provide the required weights and train speed.

\section{A. Aim of the Study:}

In the current situation of increasing speeds and train loads, special attention should be paid to improving the stability of the track formation. A deeper understanding is required for the mechanisms of dynamic load propagation from heavy haul trains to the track foundation soils and their influence on the mechanical behavior of soils, which in turn 
depends on the soil type, the water content, the degree of compaction and the type of loading. The further development of existing and creation of new technical solutions for increasing the strength and stability of the roadbed is required.

In recent years, great progress has been made in the research aimed at understanding the processes occurring in soils under the vibrodynamic effect of heavy haul trains. A great theoretical and experimental material has been obtained, which requires generalization and systematization.

\section{LITERATURE REVIEW}

So far, several reviews have been published in the field of degradation and stabilization of materials and structural elements of the railway track under the influence of heavy haul trains [2,11-21]. Most often, researchers have focused on the permanent way. Published scientific reviews refer to rails [13-16], sleepers [2,18,20], elastic elements [19]. Several recent reviews have been published with a focus on ballast and transition zones of the variable stiffness transitions between the ballast structure and man-made structures, particularly in Sol-Sánchez and D'Angelo (2017) [17] and Sañudo et al. (2016) [21]. At the same time, there are no review articles devoted to the problems of degradation and stability of the soils of the track formation under the dynamic impact of heavy haul trains. Most of the work in this area is diverse and multidirectional. However, in the last few years, there have been quite a lot of changes in this field of research, worthy of attention and discussion.

The purpose of this review is to analyze the degradation and stability of the track foundation under the heavy haul train traffic in the context of the latest scientific research and operational experience, with an emphasis on the features of the mechanisms of excitation and analysis of the consequences of the vibrodynamic impact on the soils of the foundation.

\section{EXPERIMENTAL SURVEY}

\section{A. Deterioration of Railway Track Foundation On Heavy} Haul Lines

\section{1) Description Of The Problem}

The development of rail transport in the direction of high-speed and heavy haul traffic with increased load on the axle leads to the fact that the construction of the railway track and its base becomes increasingly overloaded. The traditional railway track is not capable of providing reliability under the influence of increased axle loads and train speeds. This causes the emergence of two major problems: the deformations of the upper and the disturbances of the lower structure of the railway. In other words, the rapid growth of axle loads leads to a more intensive wear and tear of the permanent way and track formation and a shorter formation time of deteriorations in the structure of the entire railway track. As a result, additional risks arise in terms of traffic safety, as well as the cost of the railway track maintaining. Thus, the study of the dynamic processes that arise in the construction of the railway track under heavy axle loads is extremely urgent

\section{2) Deterioration Processes In Railway Track Foundation}

The railway track is a complex engineering structure that can be divided into two main components: the upper track structure (permanent way) and the track substructure (track foundation). The cross section of a railway track showing its structure is given in Fig. 1 .

The condition of both the track structure and substructure plays an important role for the safety and comfort of any kind of transportation. Effective and stable operation of the railway under the heavy haul trains is possible when its track structure is able to bear the periodic force impacts of high axle loads from heavy haul trains.

Rail track substructure is the most essential component of the railway system in view of track stability. It includes ballast and sub-ballast layers (granular layers), blanket and a subgrade. Granular layers of the railway track are packed with angular rock particles (usually 20-60 mm). The ballast is the key load-bearing layer that provides structural support against dynamic stresses caused by moving trains. It performs a number of functions :

- regulates the distribution of the loads intensity from the sleepers transferred to the roadbed;

- $\quad$ reduces the pressure from sleepers on the underlying structural layers preventing settlement of the upper structure of the track;

- providing resistance to the movement of sleepers under the influence of forces (for example, in curved sections);

- provides the necessary drainage and traping of surface water;

- accumulates fine particles within the voids.

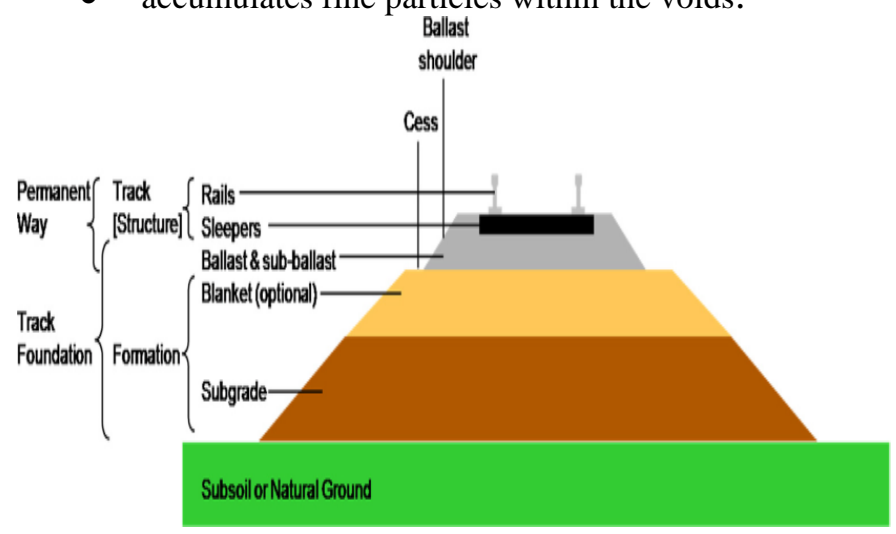

Fig.1: Section through railway track and foundation showing the ballast and formation layers.

Most deteriorations of the track geometry are usually occurs due to wear and ballast settlement. The cyclic impact of heavy haul trains on the ballast layer results in the compaction of ballast material and breakage of particles. Moreover, the compaction and attrition level of the ballast material is not uniform along the entire path (for example, ballast material and its properties may differ). This uneven compaction of the ballast layer results in roughness in the longitudinal direction and thus increases the dynamic loads on the track . 
Another super problem for the railway is the ballast fouling which is understood as major cause of track deterioration in many countries over the world. The porosity of ballast material is affected by the fouling with fine particles reducing intergranular space (Fig. 2). As a result, ballast layer drainage doesn't function properly. Poor drainage leads to accumulation of water in the ballast and lower layers of the track. In this way, the track foundation suffers from overmoistening and stability degradation and its load bearing capacity decreases.

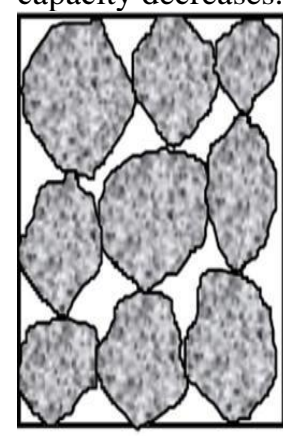

(a)

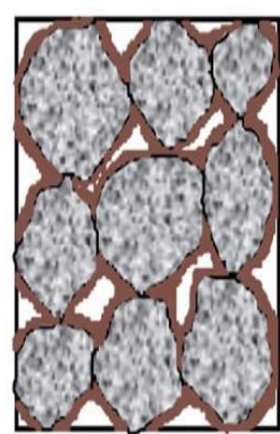

(b)

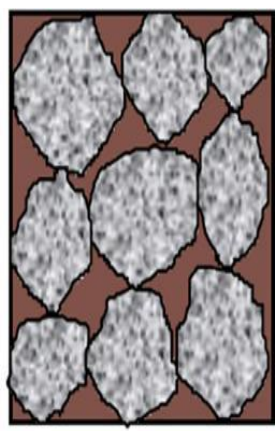

(c)
Fig. 2: Fouling status: (a) fresh ballast, (b) partially fouled ballast and (c) fully fouled ballast.

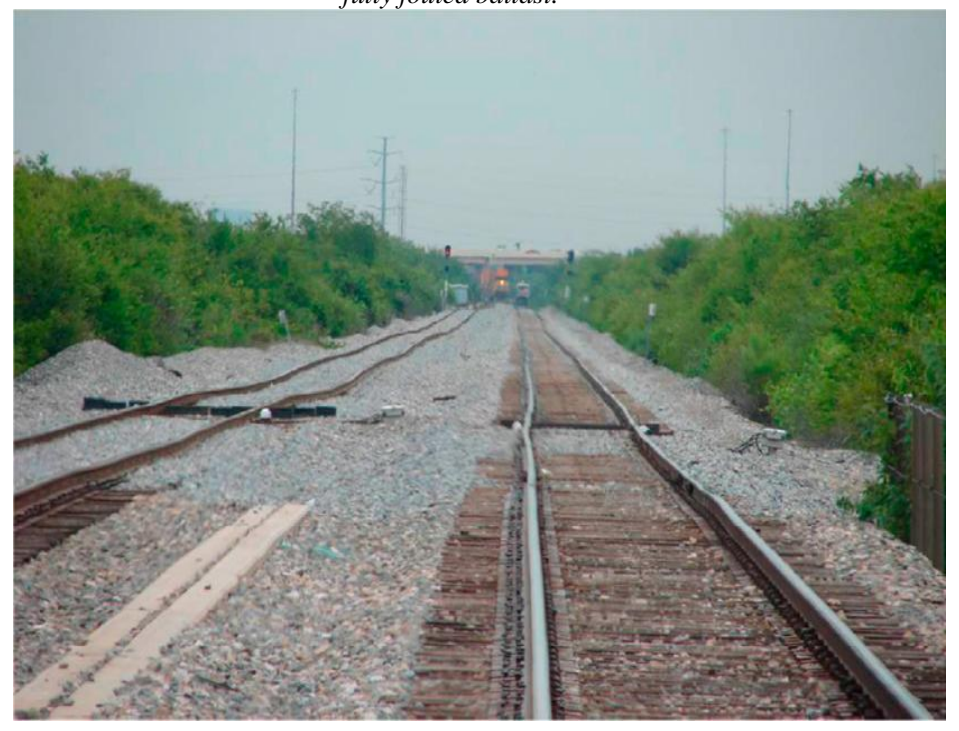

Fig. 3: Example of track geometry deformations.

\section{B. DynamicInteraction Between Heavy Haul Train and Soil} Subgrade Bed

\section{1) Vibration Induced By Heavy Haul Trains:}

Vibrations are a consequence of the movement of heavy-haul train and the contact interaction of wheels, rails and subgrade. Their impact on a track foundation increases along with the increasing maximum axle load from 7 to 40 tons. There are many parameters that affect the level and characteristics of the induced heavy haul train vibration, including, in particular, vehicle characteristics, wheel-rail interface, irregularities on the rail, geometry and stiffness of the support structure (Fig. 4).

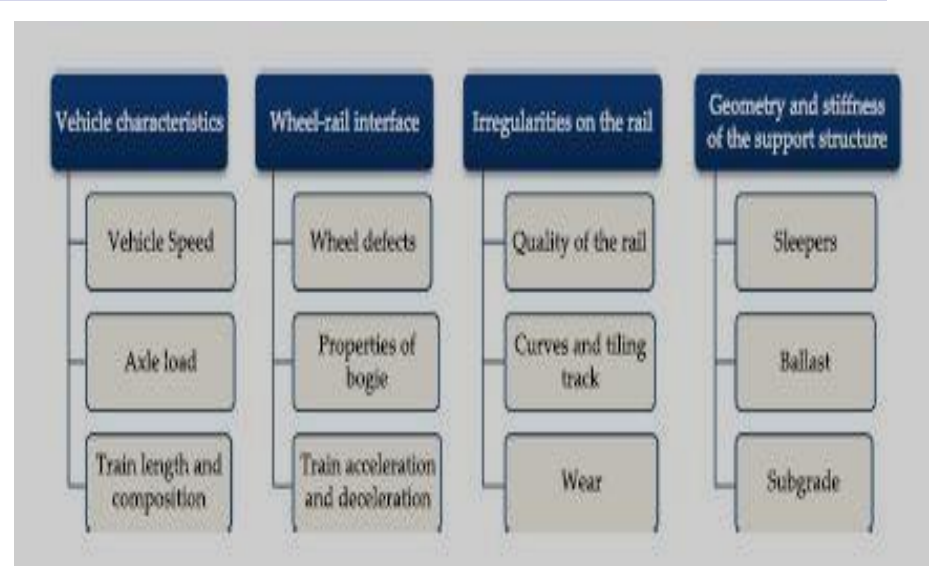

Fig. 4: The main group of characteristics affecting the induced heavy-haul train vibration.

One of the main mechanisms for excitation of ground vibrations from a moving heavy-haul train, is the quasistatic pressure created by the wheel axle on the rail track. Such pressure extends into the track foundation through the sleepers. The length of the train speed and the spacing between sleepers determine the mechanism of vibrodynamic impact characterized by temporal delay between the forces and their location in space, represented as a superposition of elastic waves transmitted into the ground.

\section{2) Degradation Of Subgrade Soil Under Loading:}

The dynamic stability of soils is important, since it is the basis for solving the problem of reducing the rigidity and strength of soils under dynamic loads from heavy haul trains. The characteristic dynamic impact from the rolling stock, transmitted from the track to the subgrade through the ballast layer, leads to various deformations in the structure of the railway track and generates stresses on the subgrade. The magnitude of the stresses and their distribution over an area depends on many factors: the characteristics of the rolling stock (first of all, the axial loads and the distances between them); train speeds; type of track superstructure; characteristics of the subgrade. The mechanism of stability degradation of the roadbed is due to the ability of soils to absorb the energy of dynamic impacts, growing under the intensive development of heavy haul transport, leading to a change in the relationship between the external force and the stability of structural bonds. At the same time, the accumulation of stresses in the places susceptible to breaking structural bonds leads to the formation of new free surfaces and, as a result, the loss of track superstructure stability. It has features in groundwater of various genesis. According to the reaction to the vibrodynamic effect, the soils composing the track foundation can be divided into Cohesive soil and Cohesionless soil. The most important factors determining the dynamic properties of track foundation besides vibrodynamic frequency and duration of impact are the mechanical characteristics: shear modulus (G) and damping ratio (D), determining its damping properties. 
The characteristic dependence of shear modulus $(\mathrm{G})$ on shear strain (c), presented on Fig. 5, makes it possible to classify geomaterials used in railway tracks by stress ranges: very small, small and large deformations. With further deformation growth, the soils become elastoplastic together with a decrease in shear modulus $(G)$ and an increase in damping ratio (D). With shear strain (c) 10-3 and more, both the shear modulus $(\mathrm{G})$ and the damping ratio (D) depend on the number of cycles and the frequency of the vibrodynamic effect. Furthermore, in, it was shown that the shear modulus $(\mathrm{G})$ and the damping ratio (D) depend on the plasticity index, PI, of the soil (Fig. 6).

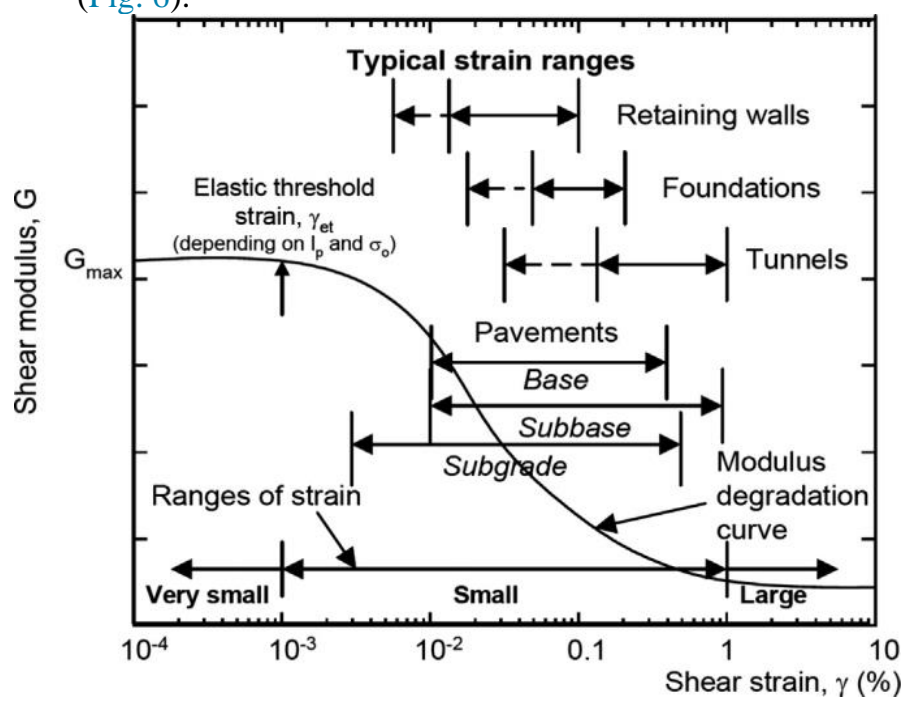

Fig. 5: Variation in shear modulus with different shear strain levels

\section{3) Cohesionless Soil:}

The vibrational processes that occur during cyclic loads in highly compressible disperse soils are accompanied by a redistribution of ground particles and an increase in its density, leading to a decrease in the sensitivity of non-cohesive soil to dynamic loads, reaching the existing critical values of density and porosity coefficient. Fig. 7 shows the characteristic behavior of non-cohesive soils with the increase of cyclic dynamic impacts from heavy haul train.

Analysis of a wide class of samples of non-cohesive soils studied in was completely generalized in, which summarized data is given in Fig. 8. Their approximations allow determining the dependence for the normalized shear modulus G/Gmax on shear strain (c) as a slowly varying hyperbolic function. The empirical relationship between shear modulus (G) and shear strain (c), determined in, is described by the following equation: $\mathrm{G} / \mathrm{G}_{\max }=1 /\left(\mathrm{a}+\mathrm{by}\left(1+10^{-\mathrm{cy}}\right)\right)$

where $a, b, c$ are the parameters that depend on the selected noncohesive soil, which are selected considering the deviation of the experimental data and the curve values for the selected $\mathrm{c}$ is minimal. When calculating the optimal values of the parameters $(a, b, c)$ for the regression function $G(c)$, the least squares method can be used to achieve a minimum discrepancy with experimental data. For approximation by the averaged data from, the parameters correspond to the values: $\mathrm{a}=$ $1.2 ; b=16 ; c=20$ and were determined with an accuracy of \pm one standard deviation. These parameters give a curve passing near the center of the data range represented in Fig. 11. A similar result was obtained earlier in for sands.
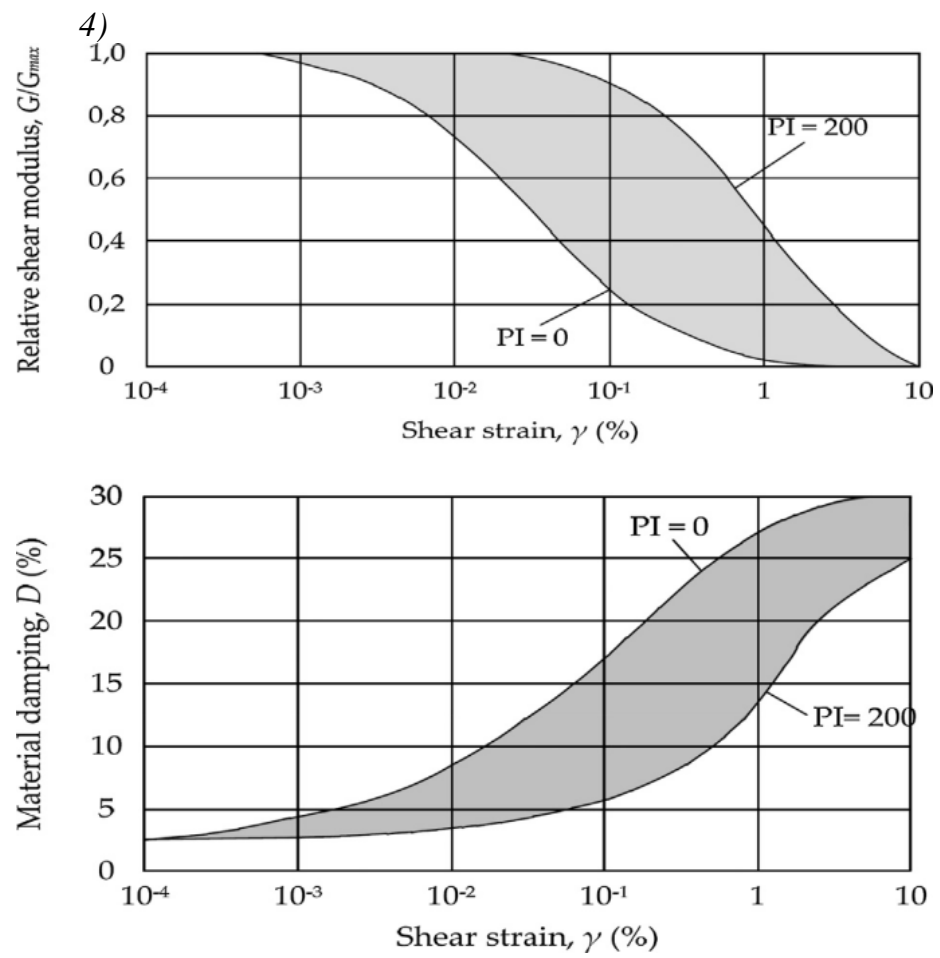

Fig. 6: Relationship between shear modulus and material damping, shear strain and plasticity index $(P I)$

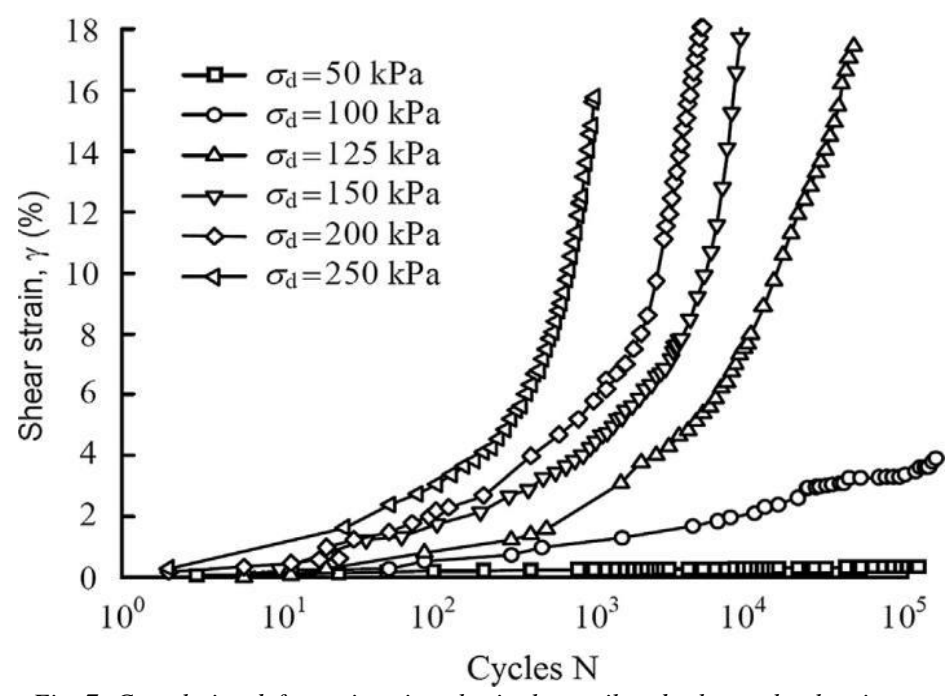

Fig. 7: Cumulative deformations in cohesionless soil under heavy-haul train loading. 


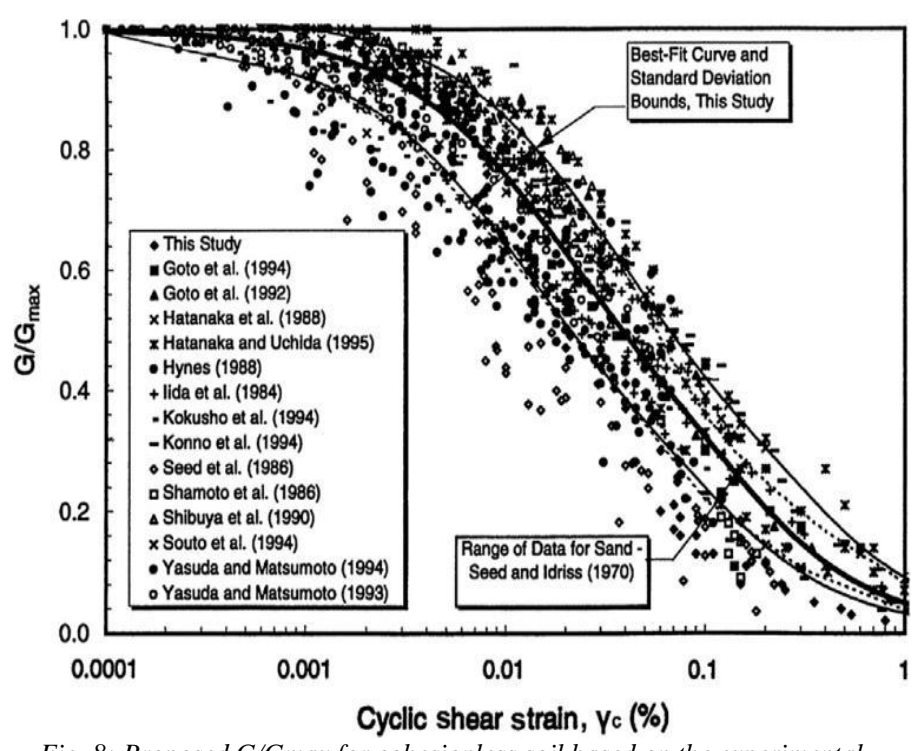

Fig. 8: Proposed G/Gmax for cohesionless soil based on the experimental results of several researchers.

\section{4) Cohesive Soil:}

Dynamic instability of cohesive soils manifests itself in the form of partial or complete (until liquefaction) loss of strength under dynamic action, which leads to large uneven settlements of engineering structures, landslide formation and other negative consequences. After vibration stop, these soils are capable of thixotropic restoration of strength, due to the complete or partial destruction of structural bonds of the soil under the action of an external load and their subsequent spontaneous restoring in rest with constant temperature, porosity and moisture. However, the ultimate strength of natural cohesive soils after the completion of the restoration, as a rule, does not reach the initial level, which is due to their quasi- thixotropic. Restoration can be partial or almost complete, when the soil is liquefied, although it is quite rare in comparison with cohesionless and weak soils. In this case, the strength changes only through adhesion, and the angle of internal friction of the soil does not change.

The effect of cyclic loads leads to the accumulation of deformation by cohesive quasi-isotropic soils (Fig. 9). For small deformations, the changes in the shear modulus (G) coefficient occur according to a quasilinear law. Gmax is constant and does not depend on the magnitude of the shear strain. The main factors affecting Gmax are the porosity coefficient and the acting voltage. The minimum value of the damping coefficient Dmin is also independent of $\mathrm{c}$ in the region of small deformations and is determined by the pore fluid and load frequency in the interval up to $10 \mathrm{~Hz}$.
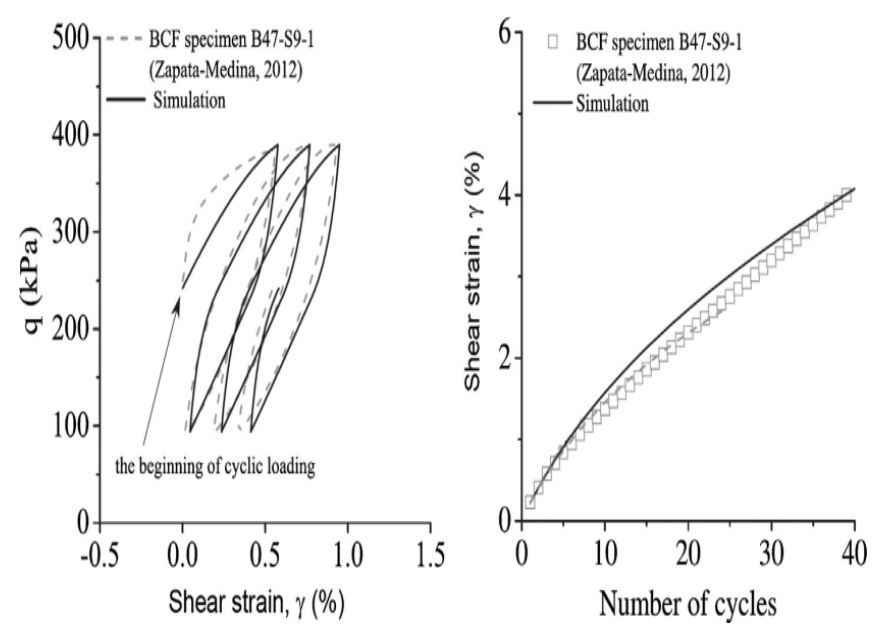

Fig. 9: Impact of cyclic loads on cohesive soils based on the experimental results of several researchers.

The growth of cyclic deformations leads to the appearance of a hysteresis effect. In this case, the possible increase in pore pressure and a decrease in the bearing capacity leads to an increase in plastic deformation. An increase in the cyclic loading time can lead to an increase in the rate of deformation, as well as when a critical number of cycles is reached, to loss of ductility of cohesive soils. Based on the results of the analysis of cyclic loads on cohesive soils in the conventional and consolidated state, it was established in that the main factor affecting the normalized shear modulus G/Gmax and the damping coefficient $\mathrm{D}$ is plasticity index $(\mathrm{PI})$, see Fig. 10. The observed regularity is due to a change in the deformation mechanism from the viscous to the hysteresis mechanism.
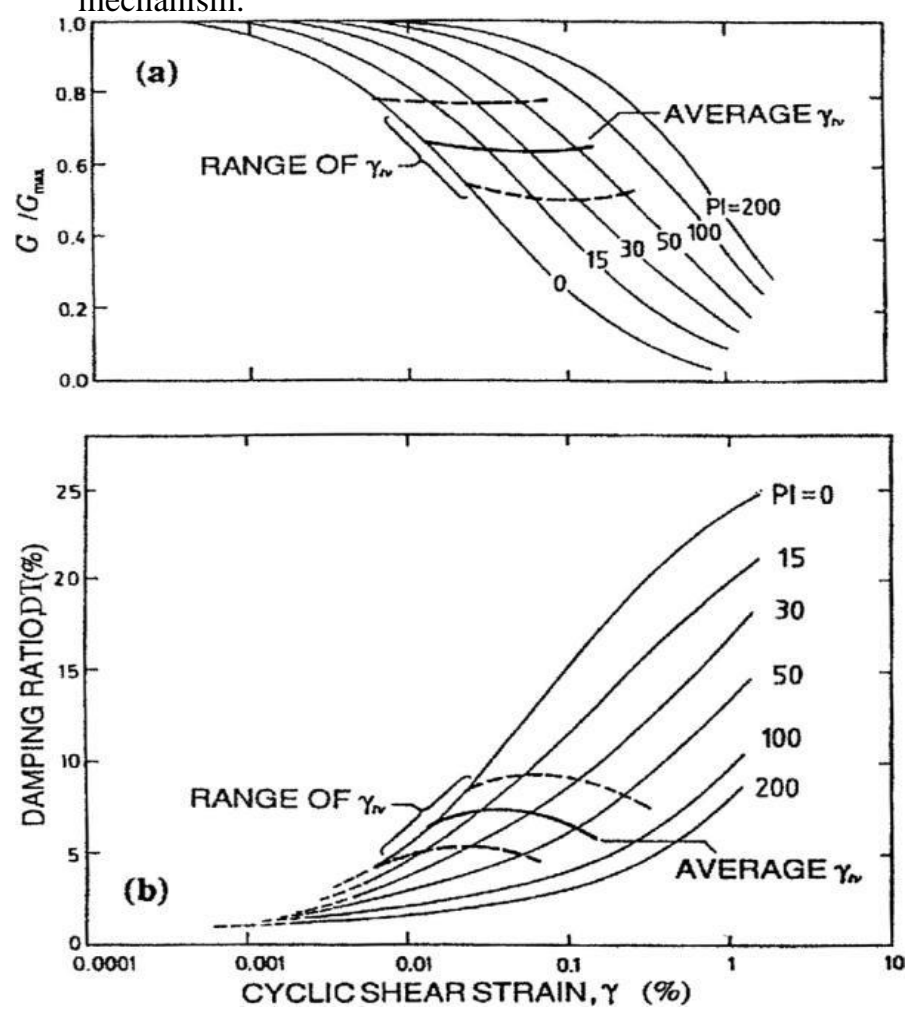

Fig. 10: Curve G/Gmax (a) and D (b) for cohesive soil based on the experimental results of several researchers. 


\section{RESULTS \& DISCUSSIONS}

\section{A. Current Solutions For Stability Improvement Of Soil Foundation In Heavy Haul Railway Tracks}

Today, various techniques and approaches have been used for the track foundation reinforcement providing its stability and the load-bearing capacity. The current techniques for improving the operational characteristics of the roadbed are given in Fig. 11. They are intended to increase the efficiency of the heavy-haul traffic. These techniques can be divided into three groups: (1) protective layers, (2) soil improvement, (3) structural solutions (Fig. 11). A wider classification of soil improvement methods, covering not only railway, but also civil engineering, can be found in the special literature.

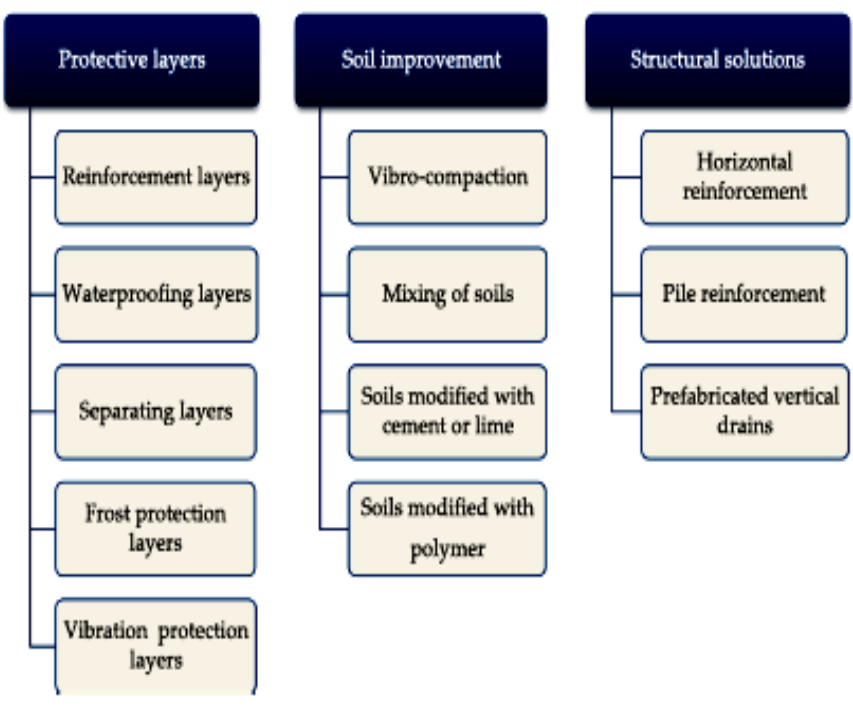

Fig. 11: The main group of methods for improving of stability of railway track foundation under heavy hauls trains.

\section{1) Protective Layers:}

One of the most effective technique for the railway subgrade reinforcement is installing the protective layers under the ballast to perform the following basic functions:

- Reinforcement - uniform distribution of the train load on the soils of the subgrade, reducing vertical stresses in order to provide the load-bearing capacity;

- Waterproofing - protection of the subgrade from atmospheric water;

- Separation - preventing mixing the particles of the ballast material and the subgrade soils;

- Frost protection - protection against freezing of the underlying frost-susceptible soils of the subgrade;

- Vibration protection - providing effective mitigation of impact and vibration damping from trains.

The effectiveness of the geogrid protective layer was confirmed by Ashpiz and Zamukhovskiy (2017) at the test site near Zelenogorsk (Russia) on the full-scale physical models of the railway construction. The heavy haul train load was simulated by a vibrating machine, providing an application to the rails of a static axle load of 25 tons. The results of the railway construction modeling without protective layers and with a protective layer reinforced with a geogrid are given in Fig. 12 and showed significantly better characteristics for the reinforced structure (Fig. 12). The results of the tests carried out by the authors were confirmed by the experimental observations of operation on the Moscow-St. Petersburg line. The results of observations showed the at comparable railway sections after reconstruction with the geogrid protective layer the track alignment correction was carried out for the 4th year, and without the protective layer - for the second year, and then every year.

A similar result is applied to the heavyweight sections was obtained by Petriaev et al. (2017) based on the results of field tests of biaxial geogrids and geocells (Fig. 13), carried out in Emperor Alexander I St. Petersburg State Transport University. When using nonwoven geotextile materials in combination with geogrids (installed directly under the geogrid), for more efficient functioning of separate components, it is possible to simultaneously provide reinforcement of the subballast layer, and also to maintain the drainage. The combination of the reinforcement function of the geogrid and the filtration and separation functions of the non-woven geotextile, prevents the movement of the fine particles of the ballast material and soil, protecting the ballast from contamination and degradation, especially in wetlands. Number of cycles

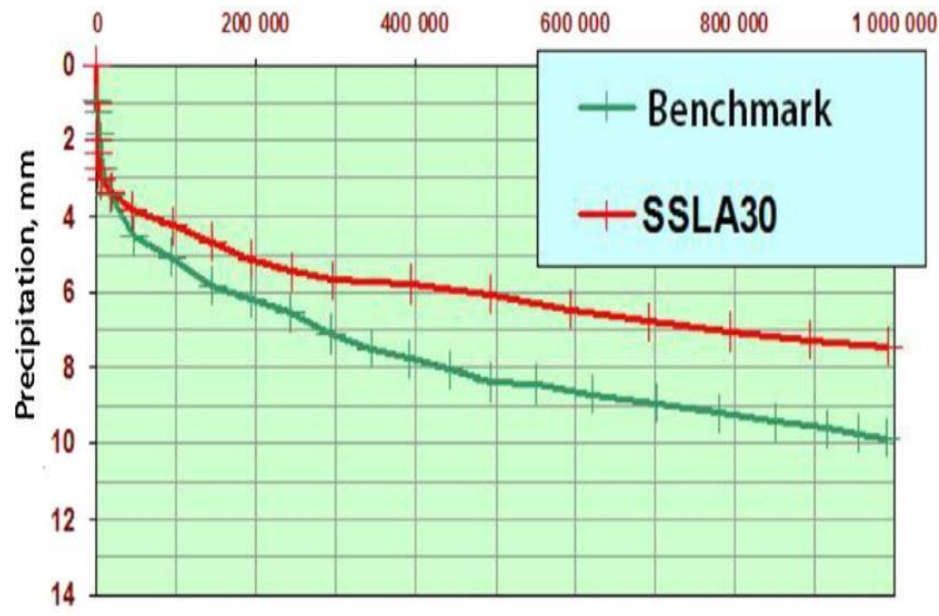

Fig. 12: The simulation results of the reinforced protective layer with geogrid (SSLA30).

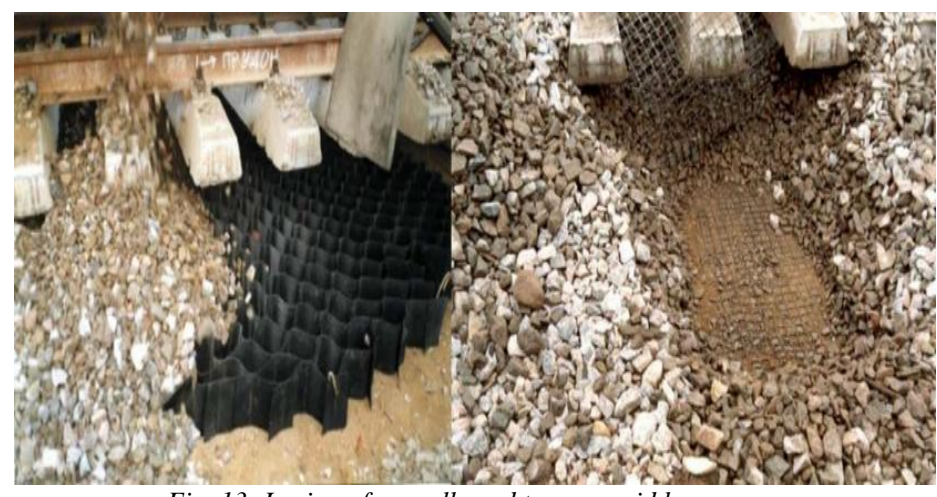

Fig. 13: Laying of geocells and two geogrid layers. 


\begin{tabular}{|c|c|c|c|c|c|c|}
\hline $\begin{array}{l}\text { Section A } \\
1200 \mathrm{~mm}\end{array}$ & $\begin{array}{l}\text { Section } \mathrm{F} \\
1200 \mathrm{~mm}\end{array}$ & $\begin{array}{l}\text { Section E } \\
1200 \mathrm{~mm}\end{array}$ & $\begin{array}{l}\text { Section D } \\
1200 \mathrm{~mm}\end{array}$ & $\begin{array}{l}\text { Section C } \\
1200 \mathrm{~mm} \\
\end{array}$ & $\begin{array}{l}\text { Section B } \\
1200 \mathrm{~mm}\end{array}$ & $\begin{array}{l}\text { Section A } \\
1200 \mathrm{~mm}\end{array}$ \\
\hline & & & & Rail (UTC 60) & & \\
\hline \multirow{2}{*}{ Ballhst 3000 min) } & HLA $(200 \mathrm{~mm})$ & HDA (150mm) & HMA $(100 \mathrm{~mm})$ & \multicolumn{2}{|c|}{ Baltast $200 \mathrm{~min}$ - } & \\
\hline & & & & HNA (150mm) & HMA $(100 \mathrm{~mm})$ & \\
\hline & & & alyet. & & & \\
\hline
\end{tabular}

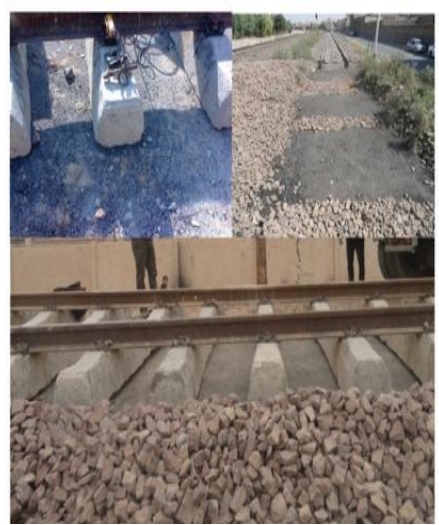

Fig. 14: Railway track construction including concrete asphalt layer.

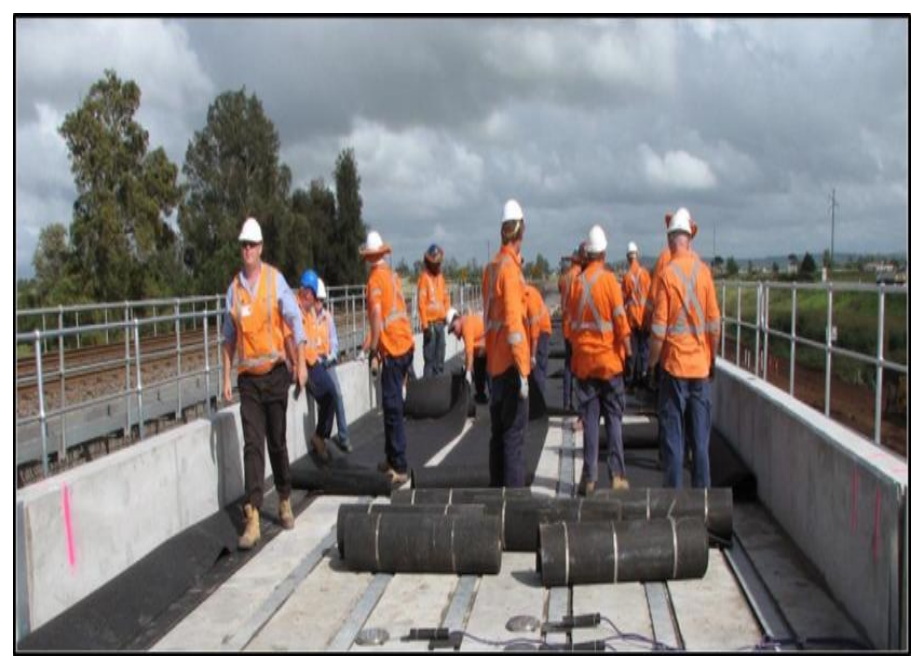

Fig. 15: Installation of placement of shockmat on concrete deck of bridge.
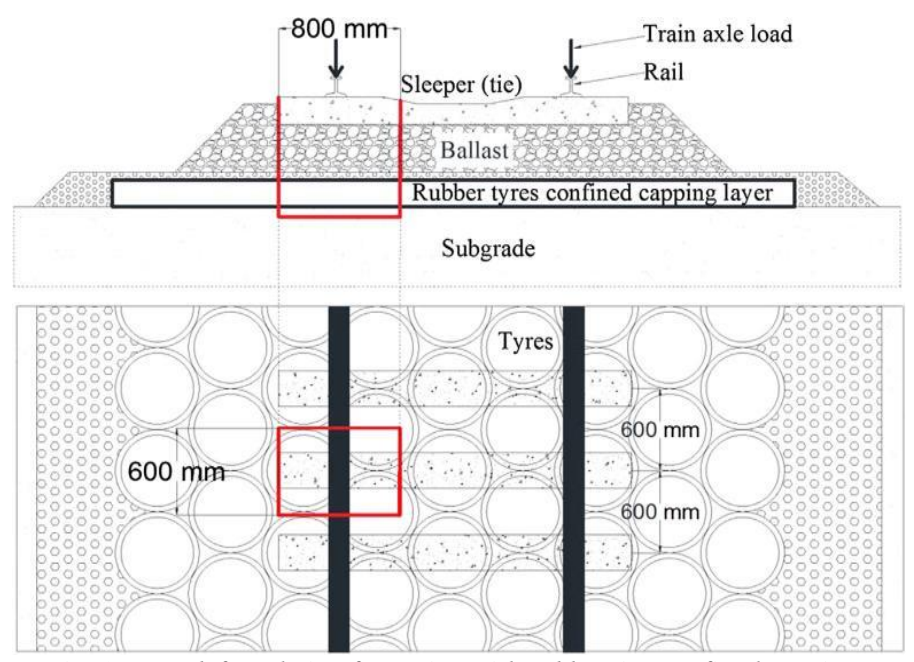

Fig. 16: Track foundation formation with rubber tire-confined capping layer.

\section{2) Soil Improvement:}

The second group of track reinforcement techniques under consideration is soil improvement methods, which are currently widely used in civil engineering. Complete replacement of substandard soils in the track foundation is the most effective way to restore its performance. However, such a technique is feasible only when the trains are completely stopped for a long period of time and only in those regions where the network of railways and highways is well developed and it is possible to redistribute traffic to other roads for the period of repairs. The way out of this situation seems to be the application of methods to increase the stability of the operating sections of the railway roadbed, based on the transformation of the initial physico-mechanical properties of soils. The essence of these methods lies in the use of various soil treatment technologies, along with partial or complete artificial transformation of their structure. These include: thermal fixing of ground with hot air and combustible fuel, electroosmosis, lowering of groundwater level, sealing by loading, vibration, use of various fibrous materials, silicification, use of enzymes, resin treatment, jet cementation bitumization, etc.. However, with regard to rail transport, the economic feasibility of the above methods is ambiguous and requires careful analysis in each specific case (on the one hand, rather cheap solutions, on the other - expensive equipment and labor-intensive strengthening works).

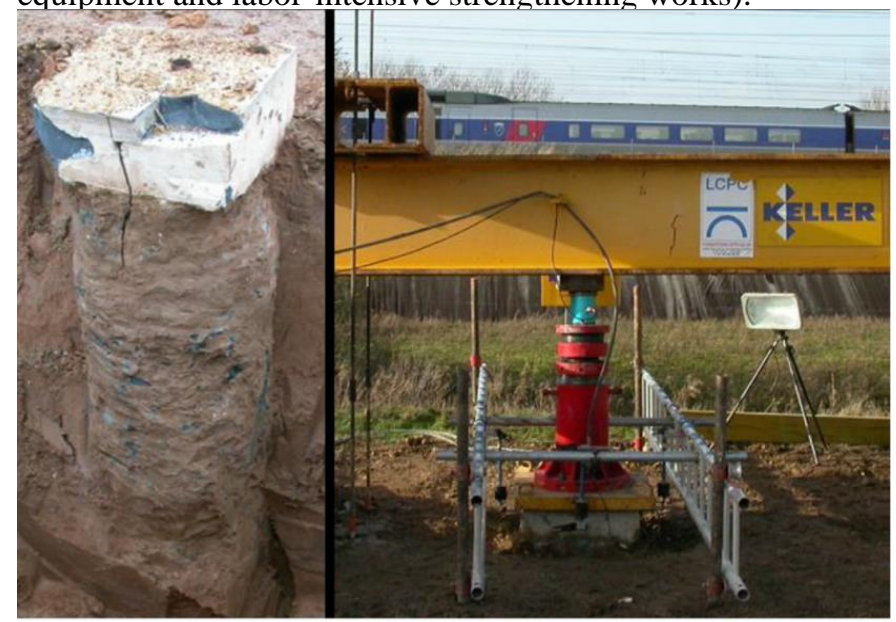

(a)

(b)

Fig. 17: View of an excavated soil-cement column(a) and view of the load test system $(\boldsymbol{b})$.
Railway subgrade reinforcement using short soil-binder columns is studied $\quad$ Different column reinforement layouts are compared and analysed
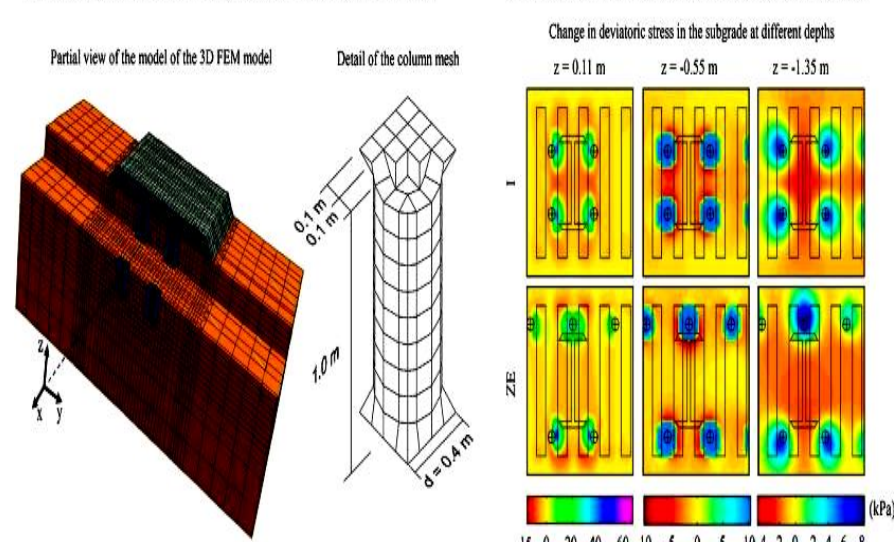

$.1502040 \quad 60 \cdot 10 \div 50510-4.2022468$

Fig. 18: Short soil-binder columns in railway track reinforcement. 


\section{Structural solutions:}

The third group under consideration is constructive solutions for increasing the stability of the track foundation soils. Study of Esmaeili and Arbabi (2015) was devoted to an experimental and theoretical study of the separated tied back-toback system (STBBS), which is a rod with support plates at the ends, and designed to stabilize high rail embankments (Fig. 24). The results of laboratory tests indicate that STBBS can increase the load capacity of the track foundation to $35 \%$. The results of numerical finite element analysis showed that with the construction of a single row of STBBS, the calculated safety factors of 10, 15 and $20 \mathrm{~m}$ embankments under a load of 25 tons per axle increase by $12.5 \%, 19.5 \%$ and $24 \%$ respectively. The use of the second row of STBBS can provide for 15 and $20 \mathrm{~m}$ embankments an increase in the safety factor by $27 \%$ and $40.4 \%$, respectively. In the subsequent works of Esmaeili and Arbabi (2017) it was shown that the increased effect of the application of the tied back-to-back system can be achieved by grouting, the use of which increases the failure load of railway embankment by up to $37 \%$ compared to the tied back-toback without groutng.

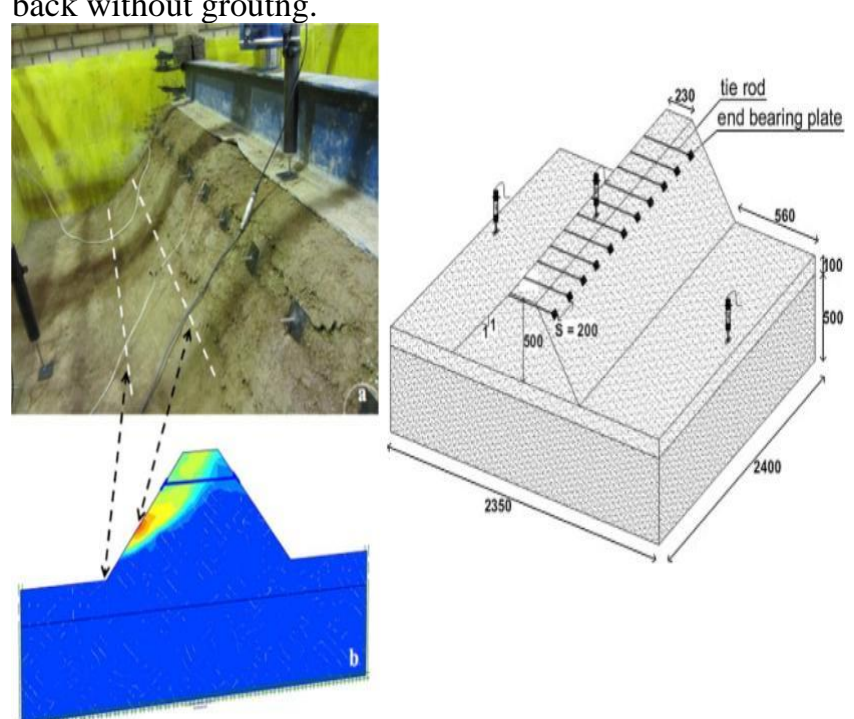

Fig. 19: Physical and Numerical Model of the separated tied back-to-back

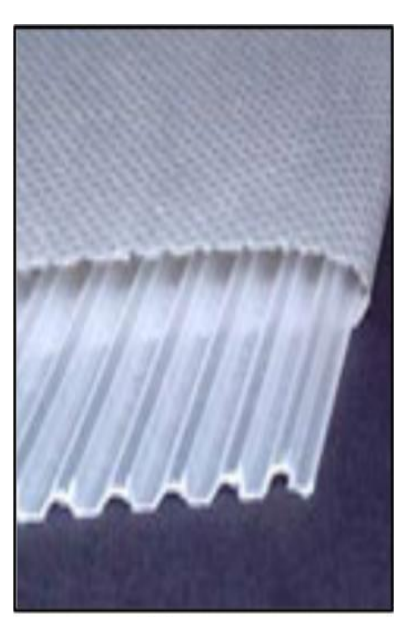

(a)

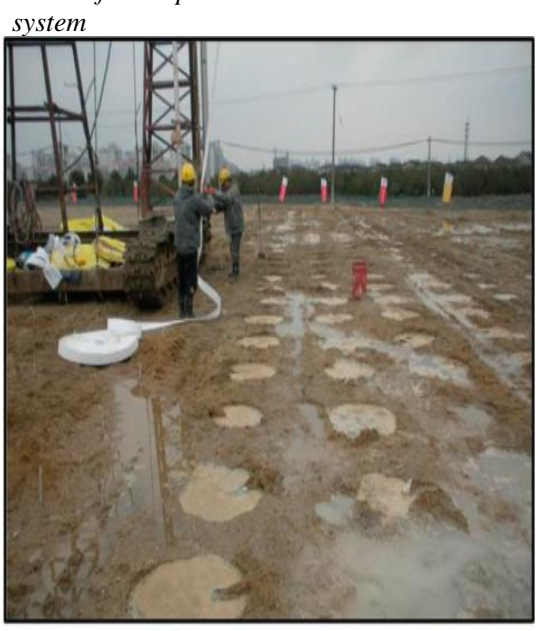

(b)
Fig. 20: A typical prefabricated vertical drains (a) and the area of field tests (b).

\section{CONCLUSIONS}

This article comprised a state-of-the-art review of dynamic behavior and stability of soil foundation in heavy haul railway tracks. From this review, the following concluding remarks can be drawn:

1. The track foundation is the most important element of the railway track construction. It is subject to intensive dynamic impact under the development of heavy haul transport. The operation of heavy trains with increased axle load results in rapid occurrence of deformations and defects in the track foundation, which increases the cost of track maintenance and the requirements for its construction.

2. Typical failures in the track foundation are mostly associated with ballast degradation and insufficient loadbearing capacity under heavy haul traffic conditions. In particular, high axle loads contribute to the uneven settlements of the ballast layer (ballast pockets); fooling the ballast material, causing drainage deterioration and consequently overmoistening the track foundation. As a result, the track foundation degrades and its load bearing capacity decreases.

3. The main factors that determine the dynamics of soil behavior of the roadbed under cyclic loads from heavy haul trains are its magnitude and duration. In the case of cohesionless soils, an increase in the number of loading cycles leads to a hyperbolic dependence on its deformation, and the steepness of this curve is determined by the amount of loading accelerating the process of shrinkage of soil with increasing accumulation of shear deformations. Stabilization of shrinkage of cohesionless soil of the track foundation reaches a maximum in the state of optimum moisture and significantly decreases with the growth of water saturation and long cyclic loads without inversion of the stress sign, leading the ground environment to liquefaction. The shear modulus in the region of small deformations is determined by the hyperbolic dependence, which rate of decrease rises with increasing fraction of the soil. The growth of the damping properties of cohesionless soils is low (_2-4\%), for small deformations substantially increases (_20\%) with prolonged cyclic loads during compaction.

4. The basis for increasing the load-bearing capacity of cohesive soils under cyclic loads from a heavy haul trains is a taxotrophic effect that ensures the complete or partial restoration of the broken structural bonds of the soil. The factors of maximum reduction in the strength of cohesive soil under dynamic impact is the time or number of cycles of impact. The influence of the frequency of cyclic impacts on the dynamic properties of cohesive soils is determined, first of all, by the duration of the action of the maximum stresses in each cycle. The balance between the accumulation of deformation and the destruction of structural bonds of ground is dense, determined by the period of cyclic loads. The complete degradation of the strength of the ground or the accumulation of critical deformations is determined by the amplitude of the acting stresses and by the acceleration, reaching _ $0.7 \mathrm{~g}$. The mechanical properties of cohesive soils in the region of small deformations, which depend only on the porosity 
coefficient and the acting stress with increasing strain, are determined significantly by the Plasticity index (PI), which is due to the change in the deformation mechanism from viscous to hysteresis.

5. The use of geosynthetics, asphalt mixtures, concrete and piles are currently the most common ways of stabilizing the railway track foundation when organizing heavy train traffic. The choice of a technical solution should be based on an integrated assessment of soil, hydrological, climatic conditions, the type of construction (embankment height, depth of excavation, steepness of slopes), based on a technical and economic comparison of options. At the same time, the wide introduction of the methods of reinforcing the roadbed in question requires the methodically correct observation of the construction and operation of experimental structures and the generalization of the results of these observations.

6. A possible direction to increase the stability of the roadbed in order to minimize uneven subsidence of the foundation is the use of impurities to existing soils to improve the mechanical properties of the subgrade soils, and to ensure quality control of soil compaction at the construction stage in order to achieve its maximum and uniform density. Conflict of interest There is no conflict of interest. Acknowledgments This work of G. Lazorenko is supported by the Russian Science Foundation under grant 17-79-10364 and performed in the Rostov State Transport University.

\section{ACKNOWLEDGMENT}

The preferred spelling of the word "acknowledgment" in America is without an "e" after the "g." Avoid the stilted expression "one of us (R. B. G.) thanks ...". Instead, try "R. B. G. thanks...". Put sponsor acknowledgments in the unnumbered footnote on the first page.

\section{REFERENCES}

[1] International Heavy Haul Association (IHHA), Guidelines to best practices for heavy haul railway operations: Infrastructure Construction and Maintenance (2009) ISBN: 1930566743, 9781930566743. pp. 650.

[2] C. González-Nicieza, M.I. Álvarez-Fernández, A. Menéndez-Díaz, A.E Álvarez- Vigil, F. Ariznavarreta-Fernández, Failure analysis of concrete sleepers in heavy haul railway tracks, Eng. Fail. Anal. 15 (12) (2008) 90-117, https://doi. org/10.1016/j.engfailanal.2006.11.021.

[3] P.J. Gräbe, C.R.I. Clayton, Effects of principal stress rotation on permanent: Deformation in rail track foundations, JGGE 135 (4) (2009) 555-565, https:// doi.org/10.1061/(ASCE)1090-0241(2009) 135:4(555).

[4] L.A. Yang, W. Powrie, J.A. Priest, Dynamic stress analysis of a ballasted railway track bed during train passage, JGGE 135 (5) (2009) 680-689, https://doi.org/ 10.1061/(ASCE)GT.1943-5606.0000032.

[5] International Heavy Haul Association (IHHA), Guidelines to Best Practices for Heavy Haul Railway Operations: Wheel and Rail, Interface (2001) 198

[6] Xu. Jingmang, Ping Wang, Yuan Gao, Jiaying Chen, Rong Chen, Geometry evolution of rail weld irregularity and the effect on wheelrail dynamic interaction in heavy haul railways, Eng. Fail. Anal. 81 (2017) 31-44, https:// doi.org/10.1016/j.engfailanal.2017.07.009.

[7] S.-W. Xiao, C.-S. Lei, Loading characteristics and dynamic response analysis of subgrade for heavy haul railway, J. Railway Eng. Soc. 31 (4) (2014) 51-56.

[8] K.-M. Guo, Y. Wang, Q.-Z. Ye, J.-L. Liu, Design research on the subgrade structure of heavy haul railway, J. Railway Eng. Soc., 31 (11) (2014) $1-5$ and 19
[9] J.-L. Liu, Q.-Z. Ye, X.-G. Song, Q. Luo, Research on the load condition and dynamic properties for heavy haul railway subgrade, J. Railway Eng. Soc, 32 (2) (2015) 33-38 and 53. [10] D. Zhang, W. Zhai, W.K. Wang, Dynamic interaction between heavy-haul train and track structure due to increasing axle load, Aust. J. Struct. Eng. 18 (3) (2017) 190-203. doi:10.1080/13287982.2017.1363126.

[11] P.J. Gräbe, C.R.I. Clayton, Designing railway formations for the future, Civil Eng./Siviele Ingenieurswese 13 (5) (2015) 16-19.

[12] B. Indraratna, S. Nimbalkar, C. Rujikiatkamjorn, A critical review of rail track geotechnologies considering increased speeds and axle loads, Geotechnical Eng. 47 (4) (2016) 50-60.

[13] R.D. Fröhling, Wheel/rail interface management in heavy haul railway operations, Applying science and technology, User Model. UserAdap. Inter. $45 \quad$ (7-8) (2007) 649-677 https://doi.org/10.1080/00423110701413797.

[14] K. Oldknow, D.T. Eadie, R. Stock, The influence of precipitation and friction control agents on forces at the wheel/rail interface in heavy haul railways, Proceedings of the Institution of Mechanical Engineers, Part F: J. Rail Rapid Transit (227(1), 2013,) 86-93, https://doi.org/10.1177/0954409712452240.

[15] X. Jin, X. Li, W. Li, Z. Wen, Review of rail corrugation progress, Xinan Jiaotong Daxue Xuebao/J. Southwest Jiaotong Univ. 51 (2) (2016) 264-273, https://doi. org/10.3969/j.issn.0258 2724.2016.02.006.

[16] R.W. Smith, W.B.F. Mackay, Austenitic manganese steels developments for heavy haul rail transportation, Can. Metall. Q. 42 (3) (2003) 333-341

[17] M. Sol-Sánchez, G. D’Angelo, Review of the design and maintenance technologies used to decelerate the deterioration of ballasted railway tracks, Constr. Build. Mater. 157 (2017) 402-415, https://doi.org/10.1016/ j.conbuildmat.2017.09.007

[18] Wahid Ferdous, Allan Manalo, Gerard Van Erp, Thiru Aravinthan Sakdirat Kaewunruen, Alex Remennikov, Composite railway sleepers - recent developments, challenges and future prospects, Compos. $\begin{array}{llll}\text { Struct. } & 134 & \text { (2015) } & \text { 158-168 }\end{array}$ https://doi.org/10.1016/j.compstruct.2015.08.058

[19] Miguel Sol-Sánchez, Fernando Moreno-Navarro, $M^{a}$ Carmen RubioGámez, The use of elastic elements in railway tracks: a state of the art review, Constr. Build. Mater. 75 (2015) 293-305, https://doi.org/10.1016/j.conbuildmat.2014.11.027.

[20] Wahid Ferdous, Allan Manalo, Failures of mainline railway sleeper and suggested remedies - review of current practice, Eng. Fail. Anal. 44 (2014) 17-35, https://doi.org/10.1016/j.engfailanal.2014.04.020.

[21] R. Sañudo, L. dell'Olio, J.A. Casado, I.A. Carrascal, S. Diego, Track transitions in railways: a review, Constr. Build. Mater. 112 (2016) 140-157.

[22] W.F. Anderson, P. Fair, Behaviour of railroad ballast under monotonic and cyclic loading, J. Geotech. Geoenviron. Eng. 134 (3) (2008) 316327.

[23] J. Lackenby, B. Indraratna, G. McDowell, D. Christie, Effect of confining pressure on ballast degradation and deformation under cyclic triaxial loading, Geotechnique 57 (6) (2007) 527-536.

[24] M. Lu, G.R. McDowell, Discrete element modelling of ballas abrasion, Geotechnique 56 (9) (2006) 651-655.

[25] B. Indraratna, P.K. Thakur, J.C., Vinod, Experimental and numerica study of railway ballast behavior under cyclic loading, Int. J. Geomech., 10(4) (2010) 136-144

[26] H. Fan, L. Gao, X.D. Xu, Simulative Calculation of the Track Strength Under the Train loaded with Overweight Freight, Railway Constr. 5 (2003) 38-39.

[27] C.Z. Zhong, Detection Countermeasure to the Marred Railway Bridge Passing the Heavy Duty Freight Cars, Railway Standard Des. 10 (2005) 80-81.

[28] Y. Sato, Japanese studies on deterioration of ballasted track Interaction of railway vehicles with the track and its substructure. Edited by Knothe, K. , Grassie, S.L. and Elkins, J .A.: Swets \& Zeitlinger, Veh. Syst. Dyn. : Int. J. Vehicle Mech. Mobility 24 (1995).

[29] M.J. Shenton, Ballast deformation and track deterioration, Trach Technology. Thomas Teleford Ltd., London, 1985.

[30] H.E. Stewart, E.T. Selig, Prediction of track settlement under traffic loading. Proceedings of the 2nd International Heavy Haul Conference. Colorado Springs, Colorado (1982).

[31] T.-S. Yoo, E.T. Selig, Field observations of ballast and subgrade deformations in track, Transport Research Record 733 (1979) 6-12. 
[32] Colin Cole, Mitchell McClanachan, Maksym Spiryagin, Yan Quan Sun, Wagon instability in long trains, Veh. Syst. Dyn. 50 (sup1) (2012) 303-317, https:// doi.org/10.1080/00423114.2012.659742.

[33] Jens C.O. Nielsen, Xin Li, Railway track geometry degradation due to differential settlement of ballast/subgrade - numerical prediction by an iterative procedure, J. Sound Vibration, 412 (2018) 441-456, ISSN 0022-460X, https://doi.org/10.1016/j.jsv.2017.10.005. [34] A.R.
Grossoni, Y. Bezin Andrade, in: Assessing the Role of Longitudinal Variability of Vertical Track Stiffness in the Long-Term Deterioration, International Association for Vehicle System Dynamics, Graz, 2015, pp. 17-21. 